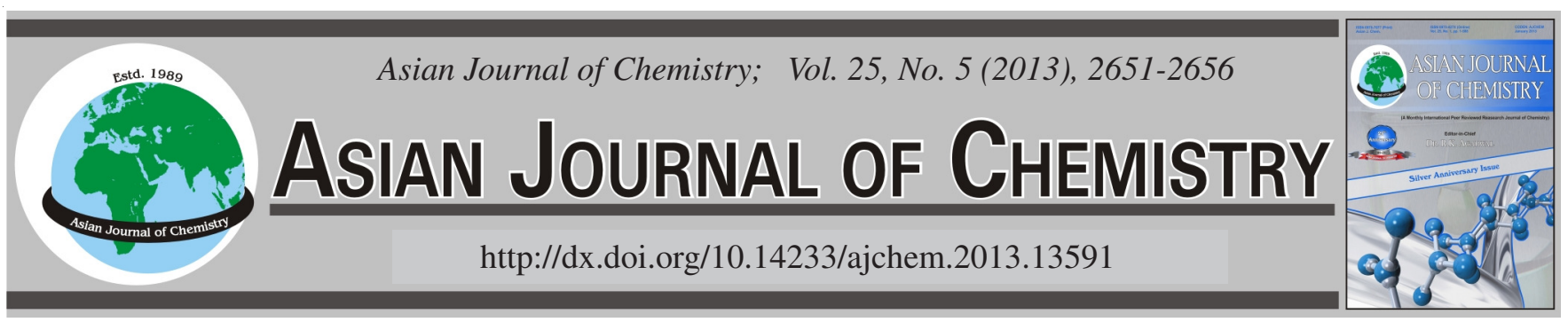

\title{
Synthesis, Characterization and Thermal Behaviour of Amino Functional Polymers from 4-Chloromethyl Styrene Polymers
}

\author{
M.H. Nasirtabrizi ${ }^{1, *}$, Z. Ghashangi ${ }^{2}$, A. Parchehbaf Jadid ${ }^{1}$ and M. Nouri Molalar ${ }^{2}$
}

${ }^{1}$ Department of Applied Chemistry, Ardabil Branch, Islamic Azad University, Ardabil, Iran

${ }^{2}$ Young Researcher Club, Islamic Azad University Ardabil Branch, Ardabil, Iran

*Corresponding author: Fax: +98 451 7722763; Tel: +98 9143544172; E-mail: nasirtabrizi@ gmail.com

\begin{abstract}
The 4-chloromethyl styrene was copolymerized with different styrenes monomers such as styrene, methyl styrene and 4-methoxy styrene by free radical polymerization at $70 \pm 1{ }^{\circ} \mathrm{C}$ using $\alpha, \alpha$-azobis(isobutyronitrile) (AIBN) as an initiator and the copolymers I, II and III collected, respectively. The copolymer compositions were characterized by ${ }^{1} \mathrm{H}$ NMR spectra and the polydispersity of the copolymers were determined using gel permeation chromatography. The phthalimide substituents were attached to the obtained copolymers with replacement of all the chlorine atoms in 4-chloromethyl styrene units. The hydrolysis of those polymers gave poly(4-aminomethyl styrene). The polymers, obtained in quantitative yields, were characterized by FTIR, ${ }^{1} \mathrm{H}$ NMR spectroscopy and dynamic mechanical thermal analysis. All the polymers containing phthalimide groups and amino groups showed a high glass transition temperature (in the range 140$150{ }^{\circ} \mathrm{C}$ ) and (in the range $120-130^{\circ} \mathrm{C}$ ), respectively in comparison with copolymers I-III (in the range $75-95^{\circ} \mathrm{C}$ ).
\end{abstract}

Key Words: Amino function polymers, 4-Chloromethyl styrene, Dynamic mechanical thermal analysis, Phthalimide.

\section{INTRODUCTION}

4-Chloromethyl styrene (CMS) or 4-vinylbenzyl chloride (VBC), is one of the most important functional monomers ${ }^{1}$. Due to the benzylic chlorine, a great number of nucleophilic substitutions are made possible, leaving the double bond undamaged and providing new monomers that can be polymerized or copolymerized ${ }^{2,3}$. In addition, 4-chloromethyl styrene can be easily polymerized or copolymerized with various initiators ${ }^{4}$ and the obtained polymers are able to react with various nucleophilic reagents, giving fairly good yields in the process ${ }^{5,6}$. Functionalized poly(chloromethyl styrene) (PCMS) or related copolymers have been widely used in different processes as bactericide polymers ${ }^{7}$, photo-sensitizers ${ }^{8}$, solar energy storage ${ }^{9}$, photo-resists ${ }^{10}$, nonlinear optics ${ }^{11}$, cholesterol trapping of human serum ${ }^{12}$ and prodrugs in biomedical applications ${ }^{13}$. Polymers containing phthalimido groups are found to possess excellent heat resistance and transparency ${ }^{14}$. Copolymers containing the phthalimide derivatives have been used as optical brightening agents ${ }^{15}$. N-Substituted phthalimide copolymers may be used as activated drug binding materials ${ }^{16}$. N-(4-Vinylbenzyl)phthalimide (VBP) or that polymers are a highly useful for the synthesis of amino group-carrying polymers with further functionalization capabilities. The structure control of polymers derived from $\mathrm{N}$-(4-Vinylbenzyl)phthalimide should be important in providing a new functional material with well-defined characteristics ${ }^{17}$.

Chemical modification of polymer structures is an important route for modification of polymer properties such as mechanical $^{18}$, thermal ${ }^{19}$ and surface properties ${ }^{20,21}$. In recently years, modification of polymer properties has been studied by attachment of various groups to macromolecular chains ${ }^{22,23}$.

There is no study about the dynamic mechanical thermal analysis (DMTA) of synthesized polymers in the literature. Thus determination of thermograms of polymers are done for the first time in this paper. Also, modification of copolymers of methyl styrene and 4-methoxy styrene with the mentioned ratios in the paper is not reported anywhere. In this research work, we report the synthesis and properties of 4-chloromethyl styrene (CMS) copolymers modified with phthalimide and amine groups. Firstly, copolymers of 4-chloromethyl styrene with styrene, methyl styrene and 4-methoxy styrene were synthesized by the free radical polymerization method. Then phthalimide groups were linked to the resulted copolymers by nucleophilic substitution reaction between sodium phthalimide salt and benzyl chloride bonds. The hydrolysis of those polymers gave poly(4-aminomethylstyrene) (PAMS). Secondly, we report the synthesis, characterization and thermal behaviour of styrenic copolymers of 4-chloromethyl styrene without and phthalimide groups and $\mathrm{NH}_{2}$ groups. The DMTA 
analysis showed that the incorporation of phthalimide groups as side chains decrease the free volume of the polymers and therefore, the rigidity and the glass transition temperature $\left(\mathrm{T}_{\mathrm{g}}\right)$ are increased.

\section{EXPERIMENTAL}

Phthalimide (Merck), 4-chloromethyl styrene (Acros, $90 \%$ ), styrene (Merck), methyl styrene (Merck, mixture of 3 - and 4-isomers with ratio of $55 \%: 45 \%$ ) and 4-methoxy styrene (Merck) were distilled under reduced pressure to remove inhibitors before using. Toluene was stirred over calcium hydride for $24 \mathrm{~h}$ and distilled in argon atmosphere. Initiator of $\alpha, \alpha^{\prime}$-azobis(isobutyronitrile) (Merck) was purified by crystallization from methanol. N,N-di-methylformamide was dried over anhydrous $\mathrm{MgSO}_{4}$ for 2 days and later with phosphoric anhydride overnight. After drying, DMF was distilled under reduced pressure.

Infrared spectra were recorded with a Bruker-IR Scientific spectrophotometer as $\mathrm{KBr}$ pellets. ${ }^{1} \mathrm{H} \mathrm{NMR}$ spectra were run on a Bruker $250 \mathrm{MHz}$ spectrometer at room temperature using $\mathrm{CDCl}_{3}$ or DMSO- $d_{6}$ as a solvent. The molecular weights $\left(\mathrm{M}_{\mathrm{w}}\right.$ and $\mathrm{M}_{\mathrm{n}}$ ) were determined using a waters 501 gel permeation chromatograph fitted with 102 and 103 nm Waters Styragel columns. The glass transition temperature was determined with a Tritec $2000 \mathrm{DMA}$ at a heating rate of $5^{\circ} \mathrm{C} / \mathrm{min}$ in air.

Copolymerization of 4-chloromethyl styrene with styrene, methyl styrene and 4-methoxy styrene: Poly(4chloromethyl styrene-co-styrene) (I), poly(4-chloromethyl styrene-co-methyl styrene) (II) or poly(4-chloromethyl styreneco-4-methoxy styrene) (III) were synthesized as following general method. In three pyrex glass ampoules, a mixture of $1.53 \mathrm{~g}(10 \mathrm{mmol})$ of 4-chloromethyl styrene, $0.065 \mathrm{~g}(0.4$ mmol) of AIBN, $1.04 \mathrm{~g} \mathrm{(10} \mathrm{mmol)} \mathrm{of} \mathrm{styrene} \mathrm{or} 1.19 \mathrm{~g}$ (10 $\mathrm{mmol})$ of methyl styrene or $1.35 \mathrm{~g}(10 \mathrm{mmol})$ of 4-methoxy styrene was dissolved in $15 \mathrm{~mL}$ of toluene, respectively.

Then the ampoules were degassed, sealed under vacuum and maintained at $70 \pm 1{ }^{\circ} \mathrm{C}$ in a water bath and shaked by a shaker machine for $c a .30 \mathrm{~h}$. Then the viscous solutions were poured from the ampoules into $150 \mathrm{~mL}$ of cooled methanol, separately. The precipitates were collected and washed with methanol for several times and dried under vacuum at room temperature to give $2 \mathrm{~g}$ of copolymer I, $2.2 \mathrm{~g}$ of copolymer II and $2.4 \mathrm{~g}$ of copolymer III.

For I: ${ }^{1} \mathrm{H} \mathrm{NMR}\left(\mathrm{CDCl}_{3}, \mathrm{ppm}\right): 1.18\left(\mathrm{CH}_{2}-\mathrm{CH}\right), 1.76\left(\mathrm{CH}_{2}-\right.$ $\mathrm{CH}), 4.5\left(\mathrm{CH}_{2}-\mathrm{Cl}\right), 6.3-7.4$ (Ar-H of styrenic); FTIR ( $\mathrm{KBr}$, $v_{\max }, \mathrm{cm}^{-1}$ ): 3024 (aromatic C-H), 2922, 2849 (aliphatic C-H), 1601, 1491 (aromatic $\mathrm{C}=\mathrm{C}$ ).

For II: ${ }^{1} \mathrm{H} \mathrm{NMR}\left(\mathrm{CDCl}_{3}, \mathrm{ppm}\right): 1.3\left(\mathrm{CH}_{2}-\mathrm{CH}\right), 1.76\left(\mathrm{CH}_{2}-\right.$ $\mathrm{CH}), 2.2\left(\mathrm{Ar}-\mathrm{CH}_{3}\right), 4.5\left(\mathrm{CH}_{2}-\mathrm{Cl}\right), 6.5-7.2$ (Ar-H of styrenic); FTIR $\left(\mathrm{KBr}, v_{\max }, \mathrm{cm}^{-1}\right): 3018$ (aromatic C-H), 2920, 2851 (aliphatic C-H), 1609, 1511 (aromatic $\mathrm{C}=\mathrm{C}$ ).

For III: ${ }^{1} \mathrm{H} \mathrm{NMR}\left(\mathrm{CDCl}_{3}, \mathrm{ppm}\right): 1.3\left(\mathrm{CH}_{2}-\mathrm{CH}\right), 1.7\left(\mathrm{CH}_{2}-\right.$ $\mathrm{CH}), 3.8\left(\mathrm{Ar}-\mathrm{OCH}_{3}\right), 4.5\left(\mathrm{CH}_{2}-\mathrm{Cl}\right), 6.5-7.3$ (Ar-H of styrenic); FTIR $\left(\mathrm{KBr}, v_{\max }, \mathrm{cm}^{-1}\right): 3025$ (aromatic C-H), 2923, 2836 (aliphatic C-H), 1608, 1510 (aromatic $\mathrm{C}=\mathrm{C}$ ).

Preparation of sodium phthalimide salt: For preparing sodium phthalimide, sodium hydride $(\mathrm{NaH})$ (10 mmol, 0.24 g) was slowly added to phthalimide $(7 \mathrm{mmol}, 1 \mathrm{~g})$ dissolved in $15 \mathrm{~mL}$ of DMF at room temperature. The mixture was stirred under nitrogen atmosphere for $0.5 \mathrm{~h}$.

Synthesis of copolymers I, II and III containing phthalimide groups: Poly(4-chloromethyl styrene-co-styrene) containing phthalimide groups (I-Pht), poly(4-chloromethyl styrene-co-methyl styrene) containing phthalimide groups (IIPht) and poly(4-chloromethyl styrene-co-4-methoxy styrene) containing phthalimide groups (III-Pht) were prepared as follows. In a $100 \mathrm{~mL}$ two-necked flask equipped with a dropping funnel and a reflux condenser, $0.5 \mathrm{~g}$ of copolymer I with $2.09 \mathrm{mmol}$ of chlorine-containing monomeric units or $0.5 \mathrm{~g}$ of copolymer II with $1.73 \mathrm{mmol}$ of chlorine-containing monomeric units or $0.5 \mathrm{~g}$ of copolymer III with $1.5 \mathrm{mmol}$ of chlorine-containing monomeric units was dissolved in $15 \mathrm{~mL}$ of DMF. A gas-inlet is attached to the top of the dropping funnel and the system is maintained under a slight pressure of nitrogen. A solution of sodium phthalimide in DMF $(15 \mathrm{~mL})$ was prepared and transferred into dropping funnel under nitrogen. Then, sodium phthalimide was added dropwise with stirring to a solution of copolymer I, II or III into flask at room temperature. The reaction mixture was refluxed for $c a$. $3 \mathrm{~h}$. Then, the solution was poured into an excess methanol and the white precipitate filtered and washed with methanol. The resulted polymer was dissolved in $10 \mathrm{~mL}$ of DMF for removing $\mathrm{NaCl}$ from the polymer. Then the remaining solution was poured into $50 \mathrm{~mL}$ of cooled methanol and washed with additional methanol for several times. The organic solution was washed sequentially with $0.2 \mathrm{M} \mathrm{NaOH}(2 \mathrm{~mL} \times 200 \mathrm{~mL})$, water $(200 \mathrm{~mL})$. Finally, the white obtained polymers containing phthalimide substituents in the side chains were collected and dried under vacuum at room temperature.

For I-Pht: ${ }^{1} \mathrm{H} \mathrm{NMR}\left(\mathrm{CDCl}_{3}, \mathrm{ppm}\right): 1.2\left(\mathrm{CH}_{2}-\mathrm{CH}\right), 1.65$ $\left(\mathrm{CH}_{2}-\mathrm{CH}\right), 4.7\left(\mathrm{CH}_{2}-\mathrm{N}\right), 6-7$ (Ar-H of styrenenic), 7.6-7.8 (Ar-H of phthalimide); FTIR (KBr, $\left.v_{\max }, \mathrm{cm}^{-1}\right)$ : 1771, 1719 (carbonyls of phthalimide).

For II-Pht: ${ }^{1} \mathrm{H}$ NMR $\left(\mathrm{CDCl}_{3}, \mathrm{ppm}\right): 1.2\left(\mathrm{CH}_{2}-\mathrm{CH}\right), 1.7$ $\left(\mathrm{CH}_{2}-\mathrm{CH}\right), 2.2\left(\mathrm{Ar}-\mathrm{CH}_{3}\right), 4.7\left(\mathrm{CH}_{2}-\mathrm{N}\right), 6.4-7.2(\mathrm{Ar}-\mathrm{H}$ of styrenic), 7.2-7.7 (Ar-H of phthalimide); FTIR ( $\left.\mathrm{KBr}, \mathrm{v}_{\max }, \mathrm{cm}^{-1}\right)$ : 1771,1716 (carbonyls of phthalimide).

For III-Pht: ${ }^{1} \mathrm{H} \mathrm{NMR}\left(\mathrm{CDCl}_{3}, \mathrm{ppm}\right): 1.2\left(\mathrm{CH}_{2}-\mathrm{CH}\right), 1.69$ $\left(\mathrm{CH}_{2}-\mathrm{CH}\right), 3.69\left(\mathrm{Ar}-\mathrm{OCH}_{3}\right), 4.7\left(\mathrm{CH}_{2}-\mathrm{N}\right), 6.4-7.2(\mathrm{Ar}-\mathrm{H}$ of styrenic), (Ar-H of phthalimide); FTIR $\left(\mathrm{KBr}, \mathrm{v}_{\max }, \mathrm{cm}^{-1}\right)$ : 1770,1715 (carbonyls of phthalimide).

Amination copolymers containing phthalimide group: The resulted polymers containing phthalimide substituents (I-Pht, II-Pht, III-Pht) $(0.5 \mathrm{~g})$ was mixed with $1 \mathrm{~mL}$ of hydrazine monohydrate in $20 \mathrm{~mL}$ ethanol. The reaction was refluxed for $30 \mathrm{~h}$. During the reaction course a white solid was precipitated. The reaction mixture was filtered and the filtrate was concentrated in vacuo. After precipitation of the filtrate into water, the resulting mixture was kept at $0{ }^{\circ} \mathrm{C}$ overnight. The off-white solid product was collected with filtration and washed with water. The solubility of aminated polymers are shown in Table-1.

For I-NH $\mathbf{N H}_{2}{ }^{1} \mathrm{H}$ NMR $\left(\mathrm{CDCl}_{3}, \mathrm{ppm}\right): 1.2\left(\mathrm{CH}_{2}-\mathrm{CH}\right), 1.7$ $\left(\mathrm{CH}_{2}-\mathrm{CH}\right), 3.6\left(\mathrm{CH}_{2}-\mathrm{N}\right)$, 6.5-7.04 (Ar-H of styrenic); FTIR $\left(\mathrm{KBr}, \mathrm{v}_{\max }, \mathrm{cm}^{-1}\right.$ ): 3356 (stretch of $\mathrm{NH}_{2}$ ), 1662 (bend of $\mathrm{NH}_{2}$ ), no signals at $1771,1719$.

For II-NH $\mathbf{N H}_{2}{ }^{1} \mathrm{H}$ NMR $\left(\mathrm{CDCl}_{3}, \mathrm{ppm}\right): 1.37\left(\mathrm{CH}_{2}-\mathrm{CH}\right), 1.78$ $\left(\mathrm{CH}_{2}-\mathrm{CH}\right), 2.2\left(\mathrm{Ar}-\mathrm{CH}_{3}\right), 4.5\left(\mathrm{CH}_{2}-\mathrm{Cl}\right), 6-7$ (Ar-H); FTIR (KBr, 


\begin{tabular}{lccc}
\hline \multicolumn{5}{c}{ TABLE-1 } \\
\multicolumn{4}{c}{ SOLUBILITY OF AMINATED COPOLYMERS } \\
\hline \multicolumn{1}{c}{ Solvent } & I-NH & II-NH & III-NH \\
\hline Chloroform & + & + & + \\
Dichloromethane & + & + & + \\
Water & - & - & - \\
DMF & + & + & + \\
DMSO & + & + & + \\
$n$-Hexane & - & - & - \\
Methanol & - & - & - \\
\hline (+): Soluble on heating. (-): Insoluble. & &
\end{tabular}

$v_{\max }, \mathrm{cm}^{-1}$ ): 3356, 3369 (stretch of $\mathrm{NH}_{2}$ ), 1662 (bend of $\mathrm{NH}_{2}$ ), no signals at 1771,1719 .

For III-NH $\mathrm{NH}_{2}{ }^{1} \mathrm{H}$ NMR $\left(\mathrm{CDCl}_{3}, \mathrm{ppm}\right): 1.2\left(\mathrm{CH}_{2}-\mathrm{CH}\right), 1.7$ $\left(\mathrm{CH}_{2}-\mathrm{CH}\right), 3.1\left(\mathrm{Ar}-\mathrm{OCH}_{3}\right), 3.6\left(\mathrm{CH}_{2}-\mathrm{N}\right), 6.5-7.03(\mathrm{Ar}-\mathrm{H}$ of styrenic); FTIR $\left(\mathrm{KBr}, \mathrm{v}_{\max }, \mathrm{cm}^{-1}\right): 3361$ (stretch of $\left.\mathrm{NH}_{2}\right), 1610$ (bend of $\mathrm{NH}_{2}$ ), no signals at 1771, 1719.

\section{RESULTS AND DISCUSSION}

Synthesis of copolymers I-III: The 4-chloromethyl styrene monomer was copolymerized with styrene, methyl styrene and 4-methoxy styrene monomers in toluene at $70 \pm 1{ }^{\circ} \mathrm{C}$ using AIBN as the radical polymerization initiator to obtain copolymers I-III in good yields. The resulted copolymers are white solid and solved in most solvent. The reaction conditions are shown in Table-2.

The FTIR spectra of copolymers I-III showed a peak around $3024 \mathrm{~cm}^{-1}$ due to $\mathrm{C}-\mathrm{H}$ stretching of the aromatic ring. The peaks around 2990 and $2950 \mathrm{~cm}^{-1}$ were attributed to the asymmetrical and symmetrical C-H stretching of methylene and methyl groups. The ring stretching vibrations of the aromatic nuclei were observed around 1601 and $1491 \mathrm{~cm}^{-1}$.

In the ${ }^{1} \mathrm{H}$ NMR spectra of the copolymers I-III, two methylene protons of benzyl chloride appeared at $4.5 \mathrm{ppm}$. The proton signals of the aryl group were seen between 6.3 and $7.4 \mathrm{ppm}$. The broad signals at 1.3 and $1.76 \mathrm{ppm}$ was due to the methylene groups of backbone. Three protons of $\mathrm{CH}_{3}$ in copolymer II and $\mathrm{OCH}_{3}$ in copolymer III appeared at 2.2 and $3.8 \mathrm{ppm}$, respectively. A typically ${ }^{1} \mathrm{H}$ NMR spectrum of the copolymer $\mathbf{I}$ is shown in Fig. 1.

Gel permeation chromatography (GPC) was used to determine the number and weight-average molecular weights of copolymers soluble in THF and the results are listed in Table-3.

\begin{tabular}{cccc}
\multicolumn{5}{c}{ TABLE-3 } \\
\multicolumn{4}{c}{ MOLECULAR WEIGHTS OF COPOLYMERS I-III } \\
\hline Copolymer & $\mathrm{M}_{\mathrm{w}}$ & $\mathrm{M}_{\mathrm{n}}$ & $\mathrm{M}_{\mathrm{w}} / \mathrm{M}_{\mathrm{n}}$ \\
\hline I & $22.1 \times 10^{3}$ & $12.2 \times 10^{3}$ & 1.8 \\
II & $22.3 \times 10^{3}$ & $11.2 \times 10^{3}$ & 2.0 \\
III & $20.8 \times 10^{3}$ & $10.4 \times 10^{3}$ & 2.0 \\
\hline
\end{tabular}

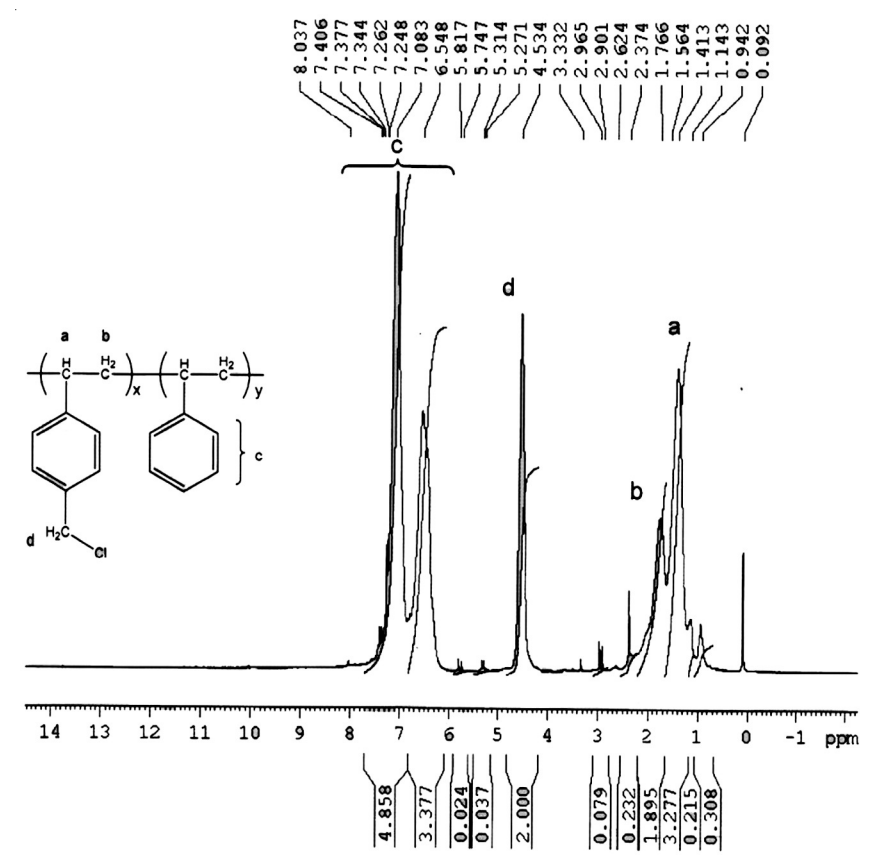

Fig. 1. ${ }^{1} \mathrm{H}$ NMR spectrum of copolymer $\mathbf{I}$ in $\mathrm{CDCl}_{3}$

The copolymer compositions were calculated from the ${ }^{1} \mathrm{H}$ NMR spectra data. The molar compositions of 4-chloromethyl styrene and styrene in copolymer I were calculated from the ratio integrated intensities of the peaks around $4.6 \mathrm{ppm}$, corresponding to two methylene protons of benzyl chloride in 4-chloromethyl styrene units to the 6.5-7.4 ppm peak area, which attributed to 9 aromatic protons of styrene units. The molar compositions of 4-chloromethyl styrene and styrene were calculated from eqns. 1 and 2 where $\mathrm{x}$ and $\mathrm{y}$ were the mole fractions of 4-chloromethyl styrene and styrene, respectively $^{24}$.

(Integrated peak area at $4.5 \mathrm{ppm}$ related to two protons of 4-chloromethyl styrene's methylen)/Integrated peak area at $6.5-7.4 \mathrm{ppm}$ related to aromatic protons of styrene

$$
\mathrm{x}+\mathrm{y}=1
$$

A similar method was used to calculate the molar compositions of methyl styrene and 4-methoxy styrene in copolymers II and III. The compositions of copolymers I, II and III are presented in Table-4.

TABLE-4

MOLAR COMPOSITION OF COPOLYMERS I-III

\begin{tabular}{ccccc}
\hline Polymer & $\begin{array}{c}\text { CMS } \\
(\mathrm{mol} \%)\end{array}$ & $\begin{array}{c}\text { Styrene } \\
(\mathrm{mol} \%)\end{array}$ & $\begin{array}{c}\text { Methyl styrene } \\
(\mathrm{mol} \mathrm{\%})\end{array}$ & $\begin{array}{c}\text { 4-Methoxy } \\
\text { styrene (mol \%) }\end{array}$ \\
\hline I & 55 & 45 & - & - \\
II & 53 & - & 47 & - \\
III & 55 & - & - & 45 \\
\hline CMS = 4-Chloromethyl styrene & &
\end{tabular}

TABLE-2

\begin{tabular}{cclcccccc}
\multicolumn{1}{c}{ TABLE-2 } \\
\multicolumn{10}{c}{ CONDITION OF PREPARATION OF COPOLYMERS I-III } \\
\hline Copolymer & Monomer of [1] & Monomer of [2] & {$[1](\mathrm{mmol} / \mathrm{L})$} & {$[2](\mathrm{mmol} / \mathrm{L})$} & Solvent & Time $(\mathrm{h})$ & Nonsolvent & Yield $(\%)$ \\
\hline I & CMS & Styrene & 10 & 10 & Toluene & 30 & Methanol & 78 \\
II & CMS & Methyl styrene & 10 & 10 & Toluene & 30 & Methanol & 81 \\
III & CMS & 4-Methoxy styrene & 10 & 10 & Toluene & 30 & Methanol & 83 \\
\hline
\end{tabular}


Attaching phthalimide groups to copolymers I, II and III: Because of the mobility of the benzyl chloride bonds in the resulted copolymers I-III, nucleophilic substitutions were possible. Therefore, sodium phthalimide as a nucleophilic reagent, made in almost quantitative yield from the reaction of $\mathrm{NaH}$ and phthalimide, was shown to be sufficiently reactive towards 4-chloromethyl styrene units in copolymers I, II and III with replacement of all the chlorine to give new copolymers with vinyl benzyl groups attached to phenyl rings via methylene spacers (Fig. 2). Phthalimide (Fig. 3), as a heterocyclic nonaromatic compound, contains a weaker acidic proton $\mathrm{N}-\mathrm{H}$ at position 8 which is deprotonated easily by strong bases such as sodium hydride $(\mathrm{NaH})$. Sodium phthalimide salt prepared for reaction with benzyl chloride bonds of copolymers. The mobility of benzyl chloride bonds in copolymers allow to react with sodium phthalimide reagents, giving I-Pht, II-Pht and III-Pht fairly good yields in the process.

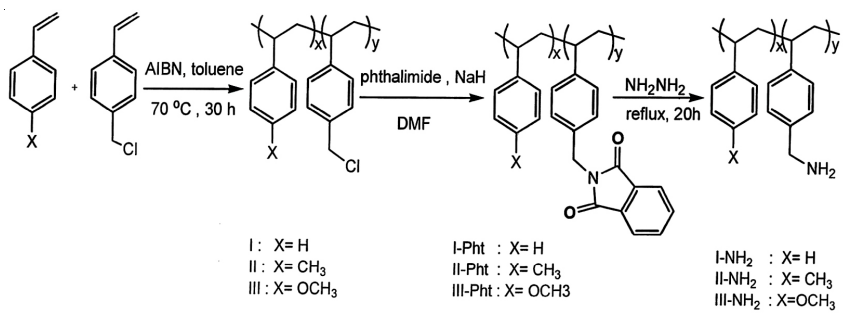

Fig. 2. Preparation of copolymers containing phthalimide groups and $\mathrm{NH}_{2}$ groups<smiles>O=C1NC(=O)c2ccccc21</smiles>

Fig. 3. Phthalimide structure

Charactization of copolymers containing phthalimide groups (I-Pht, II-Pht and III-Pht): The FTIR spectra of the copolymers I-Pht, II-Pht and III-Pht, showed two peaks at 1771 and $1719 \mathrm{~cm}^{-1}$ due to carbonyls of phthalimide groups. Due to ${ }^{1} \mathrm{H}$ NMR spectra data, with replacement of chlorine atoms with phthalimide groups, the peak around $4.5 \mathrm{ppm}$ corresponding to two methylene protons of benzyl chloride disappeared and a new peak corresponding to two methylene protons attached to phthalimide group appeared at $4.7 \mathrm{ppm}$. The proton signals of the aryl group of phthalimide were seen between 7.2 and $7.8 \mathrm{ppm}$ and show that phthalimide groups attached to synthesized copolymers.

Charactization of copolymers containing $\mathrm{NH}_{2}$ groups (I-NH $\mathbf{N}_{2}, \mathbf{I I}-\mathbf{N H}_{\mathbf{2}}$ and III-NH $\mathbf{N H}_{2}$ ): The FTIR spectra of copolymers I- $\mathrm{NH}_{2}, \mathbf{I I}-\mathrm{NH}_{2}$ and III-NH show that two peaks attribute to carbonyls of phthalimide groups disappeared. Also, twin peaks at 3356 and $3369 \mathrm{~cm}^{-1}$ is related to stretching of $\mathrm{NH}_{2}$ group and a peak at $1662 \mathrm{~cm}^{-1}$ is related to bending of $\mathrm{NH}_{2}$ group. The FTIR spectra of copolymer I before and after reactions are shown in Fig. 4.

The ${ }^{1} \mathrm{H}$ NMR spectra of copolymers $\mathbf{I}-\mathrm{NH}_{2}, \mathbf{I I}-\mathrm{NH}_{2}$ and III- $\mathrm{NH}_{2}$, indicates quantitative conversion of phthalimide groups to primary amino groups. The ${ }^{1} \mathrm{H}$ NMR spectra of those copolymers show that the peak at $4.7 \mathrm{ppm}$ attributed to two

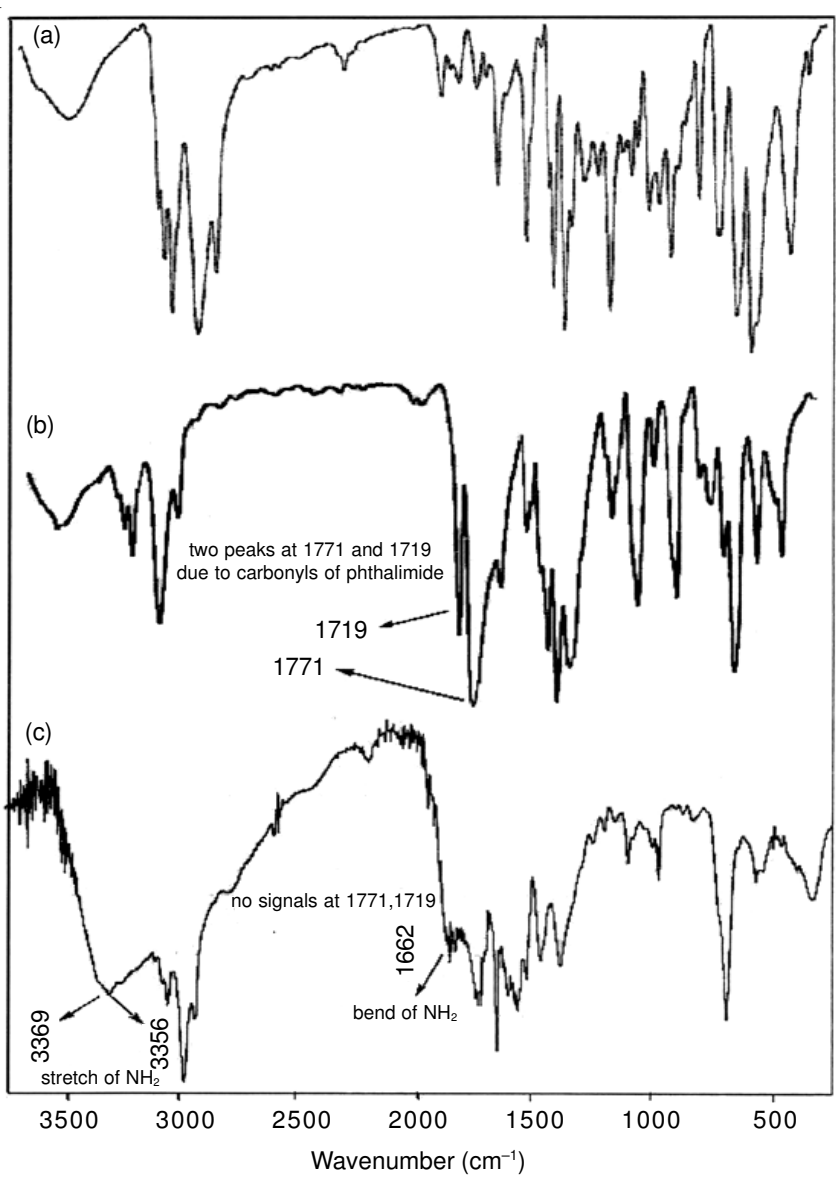

Fig. 4. FTIR spectra (KBr) of copolymers (a) I, (b) $\mathbf{I}-\mathrm{Pht}$ and (c) $\mathbf{I}-\mathrm{NH}_{2}$

methylene protons attached to phthalimide group shifted to $3.6 \mathrm{ppm}$ with broad peak corresponding to two methylene protons attached to $\mathrm{NH}_{2}$ group and disappeared two broad peaks of the aryl group of phthalimide group at 7.2-7.8 ppm. A typical spectrum of copolymer III before and after modification with phthalimide and amination is shown in Fig. 5.

Dynamic mechanical thermal analysis: The thermal behaviour of all the copolymers was investigated by DMTA analysis. DMTA diagrams of the copolymers II, II-Pht and II-NH ${ }_{2}$ are shown in Fig. 6 and their $\mathrm{T}_{\mathrm{g}}$ values are presented in Table-5. All the synthesized copolymers show a single $\mathrm{T}_{\mathrm{g}}$ showing the absence of formation of a mixture of homopolymer or the formation of a block copolymer. The DMTA analysis showed that the presence of phthalimide groups and $\mathrm{NH}_{2}$ groups lead to an increase in the glass transition temperature $\left(\mathrm{T}_{\mathrm{g}}\right)$. The incorporation of phthalimide substituents in side chains of preformed copolymers lead to significant reduction in chain flexibility and modify some properties of copolymers. The $\pi$-stacking and ring structure of the aromatic groups increases the rigidity of the polymer. This reduces the flexibility of polymer chains and hence more energy has to be induced in order to overcome the interactions. The presence of a number of carbonyl groups also adds to the rigidity of the polymer. Because the bulky group is pendant and not a part of the polymer backbone, the rise in $T_{g}$ was slight. However, it is important that $T_{g}$ 's of the polymers are high enough to withstand semiconductor processing ${ }^{25}$. Therefore, the novel polymer systems with the new physical and chemical properties and new applications 
TABLE-5

GLASS TRANSITION TEMPERATURE OF COPOLYMERS

\begin{tabular}{ccccccccccc}
\hline Copolymer & I & II & III & I-Pht & II-Pht & III-Pht & I-NH & II-NH $_{2}$ & III-NH $_{2}$ \\
\hline $\mathrm{T}_{\mathrm{g}}\left({ }^{\circ} \mathrm{C}\right)$ & 91 & 76 & 82 & 147 & 148 & 147 & 126 & 122 & 126 \\
\hline
\end{tabular}
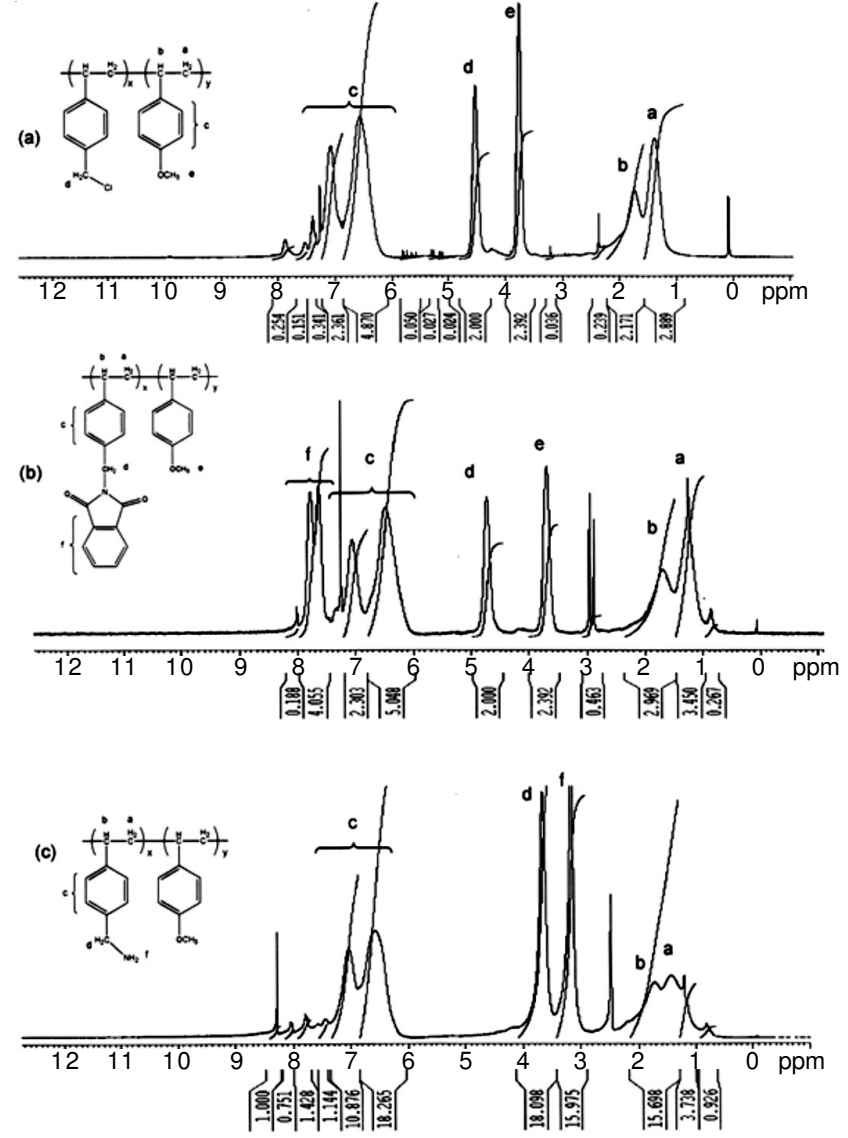

Fig. 5. Typical ${ }^{1} \mathrm{H}$ NMR spectra of copolymers (a) $\mathbf{I I I}$, (b) III-Pht in $\mathrm{CDCl}_{3}$ and (c) III- $\mathrm{NH}_{2}$ in DMSO- $d_{6}$

can be obtained. Consequently, the incorporation of the phthalimide structure in the polymer increases the chain rigidity and there with its glass transition temperature. A strong dependence of the glass transition temperature on the position of the amino function in the polymer backbone was observed. This could be explained by inter- or intramolecular hydrogen bonding ${ }^{26}$.

\section{Conclusion}

The copolymers I-III were synthesized by free radical solution polymerization. The molar compositions of the obtained copolymers were calculated by the ${ }^{1} \mathrm{H}$ NMR spectral method. The phthalimide groups as side chains were linked to copolymers from the reaction between sodium phthalimide and benzyl chloride bonds to obtain the three new modified copolymers containing phthalimide substituents. The poly(CMS) copolymers prepared here should be useful for the construction of well-defined functional polymers and novel polymeric architectures by further modification of the highly reactive amino groups in the polymers. The ${ }^{1} \mathrm{H}$ NMR spectra data showed that phthalimide and amine groups were attached to phenyl rings via methylene spacers with replacement of all chlorine atoms. The DMTA analysis indicated that the glass transition temperature of copolymers (in the range $75-95^{\circ} \mathrm{C}$

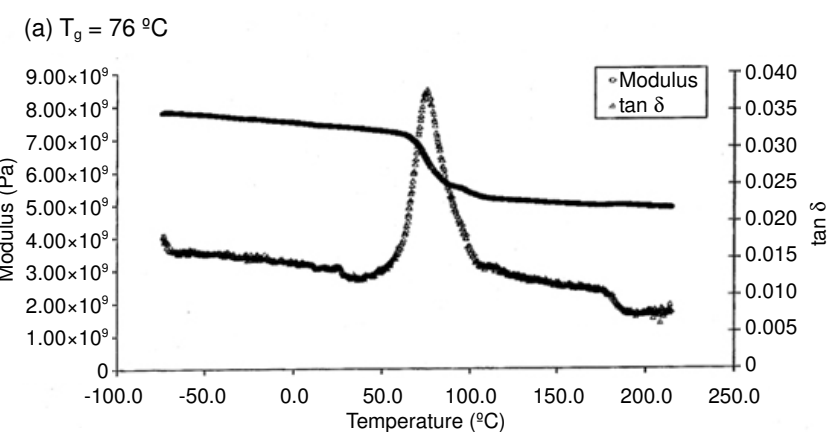

(b) $\mathrm{T}_{\mathrm{g}}=148^{\circ} \mathrm{C}$

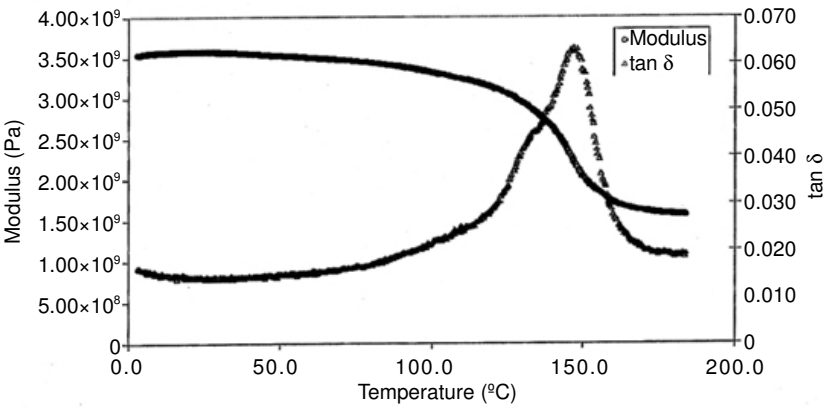

(c) $T_{g}=122{ }^{\circ} \mathrm{C}$

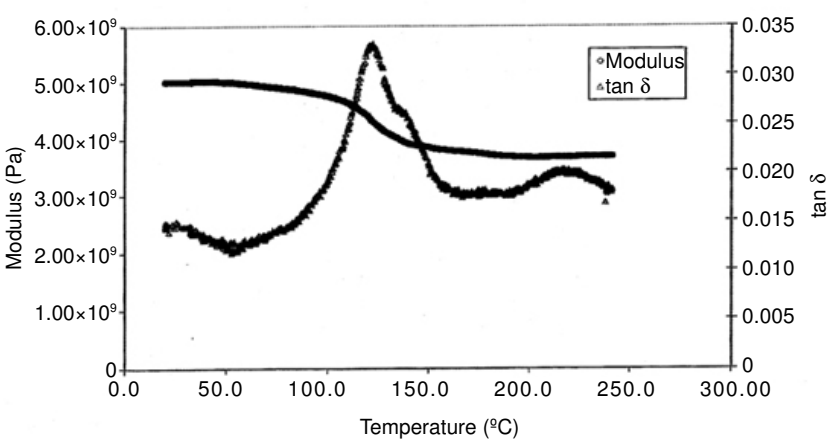

Fig. 6. DMTA diagrams of copolymers (a) II, (b) II-Pht and (c) II-NH

for I-III) increases with incorporation of phthalimide (in the range $140-150{ }^{\circ} \mathrm{C}$ for I-Pht, II-Pht and III-Pht) or amine (in the range $120-130{ }^{\circ} \mathrm{C}$ for $\mathbf{I}-\mathrm{NH}_{2}, \mathbf{I I}-\mathrm{NH}_{2}$ and III-NH${ }_{2}$ ) groups in side chains of 4-chloromethyl styrene units. The presence of the phthalimide groups into polymer structure reduces the free volume of macromolecules with modification of their properties and applications. Study of DMTA analysis showed that chemical modification of 4-chloromethyl styrene copolymers with phthalimide substituents as side chains decrease the free volume of the polymers and therefore, the rigidity and the glass transition temperature $\left(\mathrm{T}_{\mathrm{g}}\right)$ are increased. And strong dependence of the glass transition temperature on the position of the amino function in the polymer backbone was observed. This could be explained by inter or intramolecular hydrogen bonding. Another cause of preparation of poly(4-chloromethyl styrene-co-styrene) in different molar ratios of amino groups in the polymer chain firstly was that preparation with different molar ratio and secondly were identification of aminated 
polymers solution by changing of amino functional groups percentage in the polymers. Finally it was found that with increase of amino group percentage on polymers, polymers solubility in polar and nonpolar polymers is reduced.

Owing to the good reactivity of the amine groups, those polymers will then allow further modifications and easily lead, for example, to amide formation or to the grafting of various molecules.

\section{ACKNOWLEDGEMENTS}

The authors thank the Islamic Azad University of Ardabil branch for technical supports during this research.

\section{REFERENCES}

1. K.D. Safa, H.A. Eram and M.H. Nasirtabrizi, Iran. Polym. J., 15, 249 (2006).

2. J.Y. Dong, E. Manias and T.C. Chung, Macromol., 35, 3439 (2002).

3. J.P. Montheard, C. Jegat and M. Camps, J. Macromol. Sci. Polym. Rev., 39, 135 (1999).

4. M. Yus, C. Gomez and P. Candela, Tetrahedron Lett., 42, 3977 (2001).

5. L.A. Worl, WE. Jones, G.F. Strouse, J.N. Younathan, E. Danielson and K.A. Maxwell, Inorg. Chem., 38, 2705 (1999).

6. N. Kawashima, A. Kameyama, T. Nishikubo and T. Nagai, React. Funct. Polym., 55, 75 (2003).

7. A. Kanazawa, T. Ikeda and T. Endo, J. Polym. Sci. A: Polym. Chem., 31, 2873 (1993).

8. M. Babazadeh, J. Appl. Polym. Sci., 102, 633 (2006).
9. M. Babazadeh, Polym. Degrad. Stab., 91, 3245 (2006).

10. C.M. Cheng, M.I. Egbe, J.M. Grasshoff, D.J. Guarrera, R.P. Pai and J.C. Warner, J. Polym. Sci. A: Polym. Chem., 33, 2515 (1995).

11. C. Noel, K.C. Ching, M. Large, D. Reyx and F. Kajzar, Macromol. Chem. Phys., 198, 1665 (1997).

12. K. Kihara, H. Toda, M. Mori, M. Hashimoto and S. Mizogami, Eur. J. Med. Chem., 23, 411 (1988).

13. M.H. Tabrizi, S. Davaran and A. Entezami, Iran. Polym. J., 5, 243 (1996).

14. R. Jayakumar, R. Balaji and S. Nanjundan, Eur. Polym. J., 36, 1659 (2000).

15. U. Senthilkumar, R. Balaji, R. Arun Prasath and S. Nanjundan, J. Macromol. Sci.-Pure Appl. Chem., 38, 67 (2001).

16. M. Ismail, V. Veena and K.R. Animesh, J. Appl. Polym. Sci., 62, 217 (1998).

17. K. Ohno, Y. Izu, Y. Tsujii, T. Fukuda and H. Kitano, Eur. Polym. J., 40, 81 (2004).

18. K.D. Safa and MH. Nasirtabrizi, Eur. Polym. J., 41, 2310 (2005).

19. K.D. Safa, A. Hassanpour, S. Tofangdarzadeh and M.H. Nasirtabrizi, J. Iran. Chem. Soc., 5, 458 (2008).

20. Y. Mansoori, S.V. Atghia, M.R. Zamanloo, Gh. Imanzadeh and M. Sirousazar, Macromol. Nanotechnol., 46, 1844 (2010).

21. K.D. Safa, M.H. Nasirtabrizi and S. Tofangdarzadeh, Iran. Polym. J., 17, 39 (2008).

22. U. Georgi, M. Erber, J. Stadermann, M. Abulikemu, H. Komber, A. Lederer and B. Voit, J. Polym. Sci. A: Polym. Chem., 48, 2224 (2010).

23. S. Moulay, Prog. Polym. Sci., 35, 303 (2010).

24. D. Zhang, T. Zhang, J. Deng and W. Yang, React. Funct. Polym., 70, 376 (2010).

25. M. Guntupallia, C.W. Wilkins and P.E. Cassidya, Int. J. Polym. Mater., 57, 442 (2008).

26. A. Parthiban, A. Le Guen, Y. Yansheng, U. Hoffmann, M. Klapper and K. Müllen, Macromol., 30, 2238 (1997). 